\title{
A Scoping Systematic Review: Needs Assessments Approaches to Inform Continuous Professional Development for Health Professionals
}

Muna Al-Ismail ${ }^{1 *}$, Zachariah Nazar ${ }^{1}$,Derek Stewart 1 , Tarteel Hussain 1 ,Lina Naserallah ${ }^{2}$,Alaa Daud ${ }^{3}$, Hadi Abu Rasheed $^{4}$ 1Qatar University, College of Pharmacy; ${ }^{2}$ Hamad Medical corporation; ${ }^{3}$ Qatar University, College of Dental Medicine, ${ }^{4}$ Qatar Cancer Society, Qatar
${ }^{*}$ Corresponding author: muna.alismail@qu.edu.ga

\section{Background}

- Within the healthcare professions, the need for continuing professional development (CPD) is wellestablished $^{1}$

A rigorous learning needs assessment (LNA) is a crucial initial step in the educational process involving defining its purpose, a systematic approach to its design and dissemination, and the use that will be made of the findings ${ }^{2}$

The literature reports diverse approaches in conducting LNAs for the purpose of informing healthcare CPD activities; perspectives of various stakeholders have been investigated, and different measures have been evaluated including perception, attitudes, knowledge and competency ${ }^{3}$

A search of the peer-reviewed literature and indeed guidance provided by CPD accrediting bodies fails to provide practical guidance on how they should be optimally performed ${ }^{4}$

\section{Objectives}

- The purpose of this research is to collate and summarize the reported methods adopted for conducting a LNA in the context of health professional CPD

\section{Methods}

- For the purpose of this scoping systematic review, the definition of "needs assessment" was as follows: a systematic process for determining and addressing needs or gaps between current conditions and desired conditions ${ }^{5}$.

\begin{tabular}{|c|c|}
\hline $\begin{array}{l}\text { Database } \\
\text { and grey } \\
\text { literature }\end{array}$ & $\begin{array}{l}\text { - PubMed, Embase, CINAHL, ERIC, IPA, APA } \\
\text { PsycArticles } \\
\text { - Google Scholar } \\
\text { - OpenGrey, Grey Literature Report }\end{array}$ \\
\hline $\begin{array}{l}\text { Search } \\
\text { terms }\end{array}$ & $\begin{array}{l}\text { - Professional education, continuing } \\
\text { professional development, professional } \\
\text { development, continued professional } \\
\text { development AND needs assessment, } \\
\text { training needs assessment, learning needs } \\
\text { assessment, needs analysis AND health } \\
\text { personnel, clinician, healthcare practitioner }\end{array}$ \\
\hline Inclusion & $\begin{array}{l}\text { - Type of study: Primary research studies of } \\
\text { any design conducted with any health } \\
\text { professional grouping which reported } \\
\text { outcomes relating to needs assessment } \\
\text { - Language: English } \\
\text { - Date: from database inception until the end of } \\
\text { August } 2020\end{array}$ \\
\hline $\begin{array}{l}\text { Study } \\
\text { selection }\end{array}$ & $\begin{array}{l}\text { - Two reviewers independently screened } \\
\text { title/abstract, and then full text }\end{array}$ \\
\hline $\begin{array}{l}\text { Data } \\
\text { extraction }\end{array}$ & $\begin{array}{l}\text { - Needs assessment participants; method of } \\
\text { sampling; development of any needs } \\
\text { assessment tool; outcome measures, } \\
\text { including specific domains; details of how the } \\
\text { results of needs assessment were to be used }\end{array}$ \\
\hline
\end{tabular}

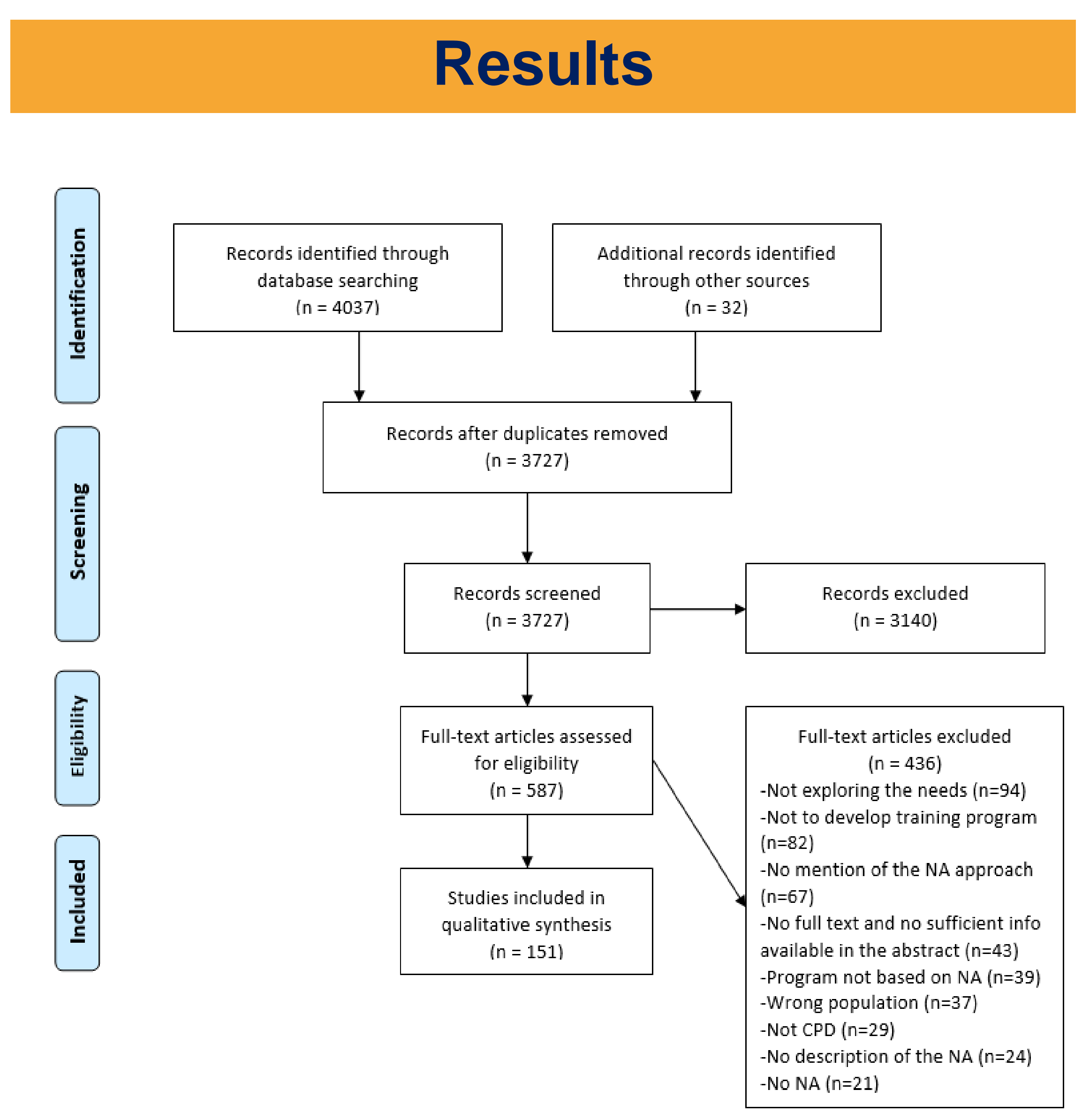

Figure 1. PRISMA Flowchart of paper selection process

Country

- USA ( $n=42)$, UK $(n=34)$, Canada $(n=21)$, Australia $(n=12)$, others $(n=63)$

\section{Setting}

- Primary care $(n=40)$, secondary care $(n=39)$, tertiary care $(n=19)$, others $(n=5)$

\section{Method of needs assessment}

- The majority of studies adopted quantitative methods ( $\mathrm{n}=$ $85)$, with mixed-methods $(n=45)$ and qualitative methods $(n=24)$ used less frequently

\section{Stakeholders}

- The majority of studies reported the needs assessment from the perspective of clinicians $(n=144)$

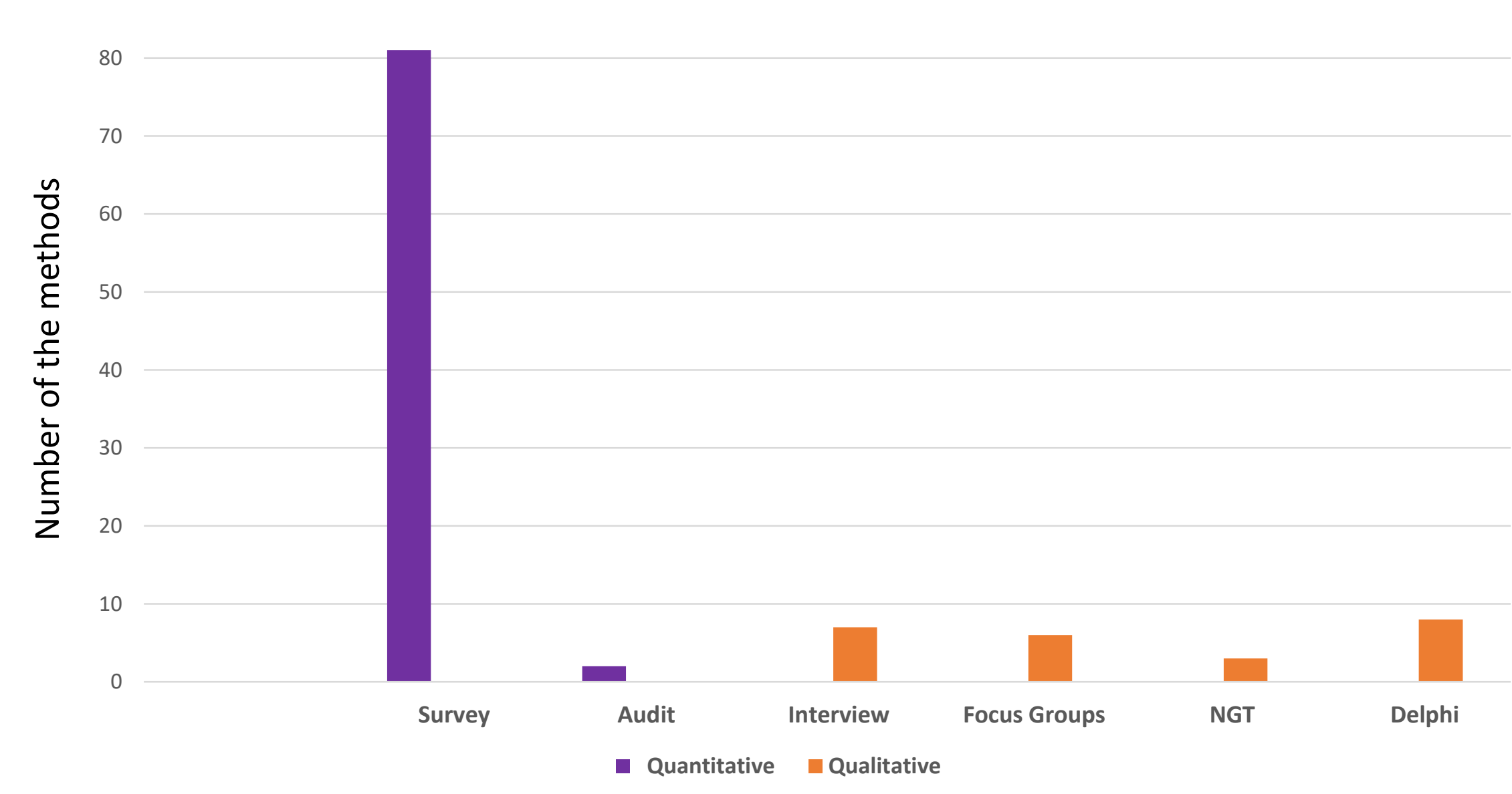

Figure 2. Methods adapted for needs assessment

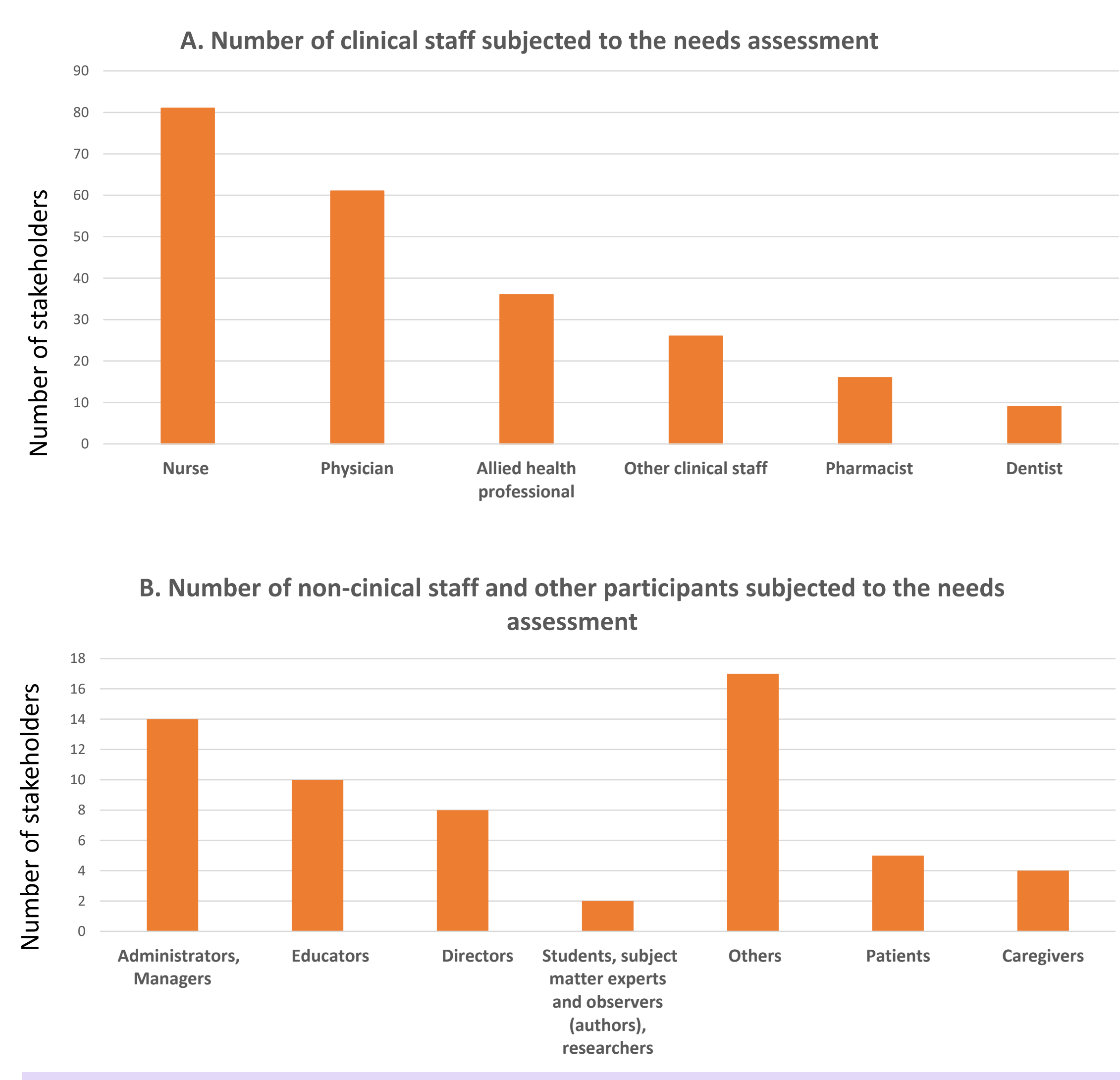

Figure 3. Stakeholders subjected to the needs assessment

\section{Results (Cont'd)}

\section{Outcome measures}

- There were various outcome measures (e.g. knowledge, skills, confidence) evaluated in the needs assessment methods

- There were $n=101$ studies which used either a single method or multiple methods to explore learning needs using numerous outcome measures
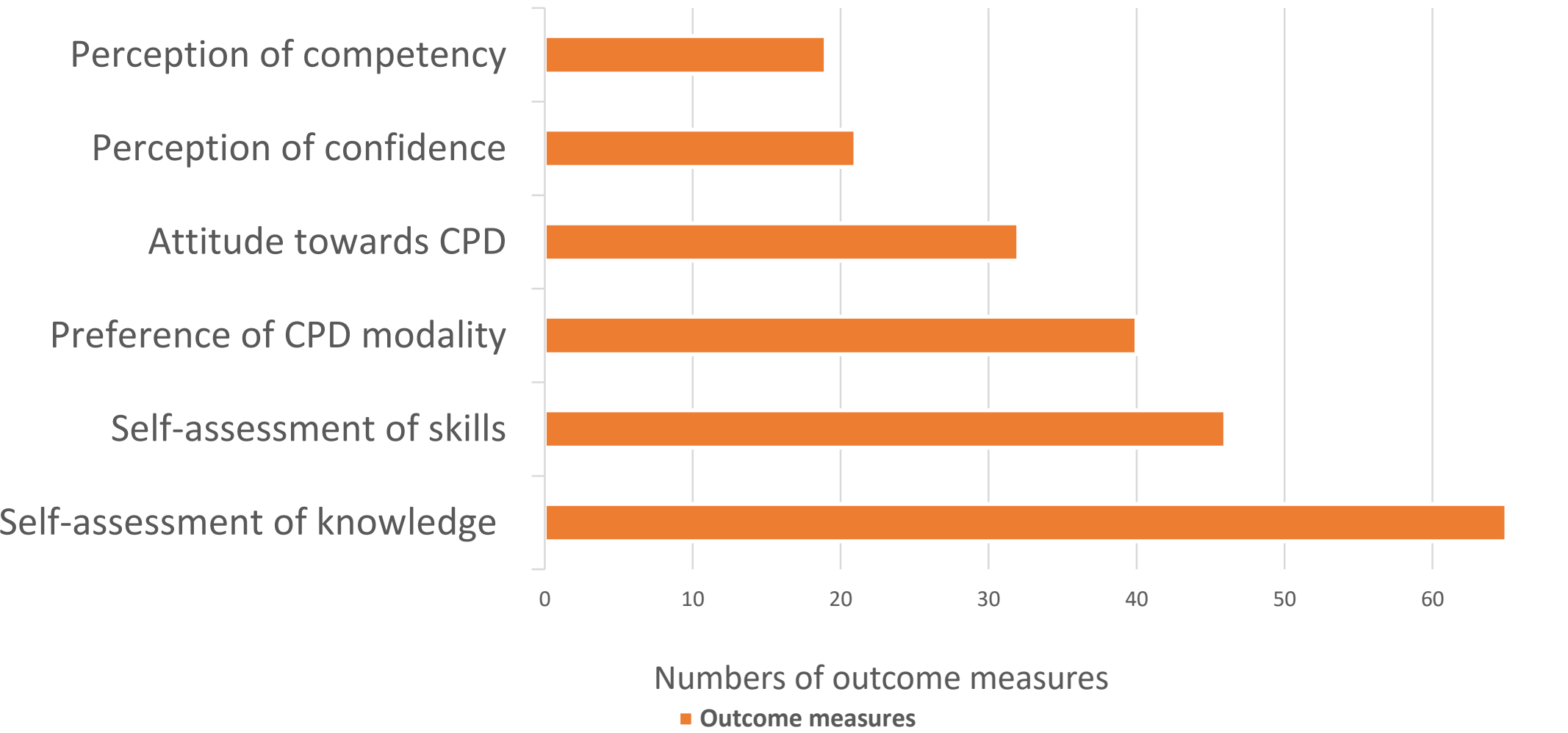

Figure 4. Examples of reported outcome measures Outcome utilization

- Majority of the study findings reported to inform future CPD content and delivery $(n=92)$

- Little details were provided to describe how the findings were used

- Minority of studies indicated the subsequent development of an educational program or workshop series

\section{Limitations}

- The majority of studies were conducted in western countries, where health systems and supporting infrastructure are likely to be significantly different to other settings. Thus, the potential generalizability and transferability of the findings may be limited

- The search was limited to articles published in English

The quality of the included studies was not assessed

\section{Conclusion}

The findings from this study demonstrate the lack of published evidence of systematic and comprehensive approaches to needs assessments for the purpose of informing CPD for healthcare professionals

- Surveys as a single method, was the approach adopted in approximately half of the needs assessments

- A minority of studies described the employment of objective tools to for the LNA

- Future studies that aim for developing systemic LAN approaches are recommended

\section{References}

Ramani S, McMahon GT, Armstrong EG. Continuing professional development to foster behaviour change: from principles to practice in health professions education. Medical teacher. 2019;41(9):1045-1052.

2. Pilcher J. Learning needs assessment: Not only for continuing education. Journal for nurses in professional development. 2016;32(4):185-191.

3. Hauer J, Quill T. Educational needs assessment, development of learning objectives, and choosing a teaching approach. Journal of palliative medicine. 2011;14(4):503-508.

Pocock L, Rezaeian M. Medical Education and the Practice of Medicine in the Muslim countries of the Middle East. Middle East Journal of Family Medicine. 2016;7(10):28.

5. Arksey H, O'Malley L. Scoping studies: towards a methodological framework. International journal of social research methodology. 2005;8(1):19-32. 